\title{
Outcomes and Disease Spectrum of LBW Neonates in a Secondary Health Facility
}

\author{
Rosena Olubanke Oluwafemi $\mathbb{D}^{1},{ }^{1}$ Femi Peter Adesina $\mathbb{D}^{D},{ }^{2}$ and Adebola Olutoyin Hassan ${ }^{3}$ \\ ${ }^{1}$ Paediatrics Department, Mother and Child Hospital, Akure, Nigeria \\ ${ }^{2}$ Department of Biology, Federal University of Technology Akure, Akure, Nigeria \\ ${ }^{3}$ Family Health Department, UNICEF, Abuja, Nigeria \\ Correspondence should be addressed to Rosena Olubanke Oluwafemi; bankyfem@yahoo.com
}

Received 27 March 2021; Revised 23 December 2021; Accepted 10 January 2022; Published 27 January 2022

Academic Editor: Mihajlo Jakovljevic

Copyright (C) 2022 Rosena Olubanke Oluwafemi et al. This is an open access article distributed under the Creative Commons Attribution License, which permits unrestricted use, distribution, and reproduction in any medium, provided the original work is properly cited.

\begin{abstract}
Globally, 30 million low birth weight (LBW) babies are born every year and 95\% of them are from developing countries. LBW neonates are at a high risk of mortality, morbidity, and long-term disability. The objective of this study is to investigate outcomes and disease spectrum among low birth weight neonates. This is a prospective, observational study conducted on 540 neonates admitted in the Mother and Child Hospital, Akure, Ondo State, Nigeria, from 2017 to 2018. Questionnaire, interview, clinical, and diagnostic procedures were used as research tools. There were 137 low birth weight (LBW) neonates, with the mean mothers' age of $31.92 \pm 6.60$. Of the 540 neonates, $69(50.4 \%)$ and $68(49.6 \%)$ were term and preterm, respectively. There were 64 female neonates (46.7\%) and 73 male neonates (53.3\%). The mean weight of the neonates was $1.82 \pm 0.44 \mathrm{~kg}$, and mean number of days on admission was $6.42 \pm 6.75$ days. Neonatal sepsis (NNS) was the highest morbidity 51 (37.2\%) among the LBW neonates, followed by prematurity $47(34.4 \%)$ and neonatal jaundice (NNJ) $18(13.1 \%)$. Sex $\left(\chi^{2}=3.584, p=0.310\right)$, mode of delivery $\left(\chi^{2}=4.669\right.$, $p=0.198)$, and gestational age $\left(\chi^{2}=3.904, p=0.272\right)$ were not a significant determinant of outcome among LBW neonates. Men were 2.36 times more likely to be preterm $(\mathrm{OR}=2.36,95 \% \mathrm{CL}=1.01-5.54, p=0.048)$ among LBW neonates. Outcomes of LBW neonates who were delivered by SVD were not significant compared to preterm delivered by CS (OR $=0.46,95 \% \mathrm{CL}=0.13-1.65$, $p=0.096)$. Sixty percent $(60 \%)$ of the mothers had Prolonged Rupture of Membranes (PROM). Morbidities such as hypothermia (72.2\%), apnoea (63.6\%), haemorrhagic disease of the newborn (HDN) (66.7\%), and respiratory distress syndrome (RDS) (66.7\%) were more observed with preterm LBW neonates. Importance of qualitative antenatal care (ANC) should be emphasized; anticipation and prevention of LBW births can help mitigate some of the problems they are prone to.
\end{abstract}

\section{Introduction}

Neonate's birth weight can be categorized to be low birth weight $(<2,500 \mathrm{~g})$, normal birth weight $(2,500$ to $4,000 \mathrm{~g})$, and high birth weight $(>4,000 \mathrm{~g})[1]$. Low birth and high birth weight are called abnormal birth weights (ABW) $[2,3]$. Two major determinants of birth weight include the gestational age and intrauterine growth rate [4] and this means low birth weight is either as a result of prematurity $(<37$ completed weeks), intrauterine growth restriction, or both [5], the latter being primarily as a result of intrauterine malnutrition from altered placental circulation.
Globally, 30 million of low birth weight (LBW) occurs every year and $95 \%$ of them are from developing countries $[6,7]$. Low birth weight is a major contributory factor to neonatal ill health and by extension child morbidity, mortality, and disability [8-10]. A cohort study on cognitive abilities, educational progress, and behavioral problems in very low birth infants followed up for 8 years showed they all lagged behind the controls (birth weight $>2499$ g) [11]. By WHO definition, low birth weight is a birth weight of $<2,500 \mathrm{~g}$ [12]. Low birth is further classified into extremely low birth weight $(\leq 1,000 \mathrm{~g})$ and very low birth weight $(<1,500 \mathrm{~g})[13]$. 
Several factors have been associated with low birth weight though not necessarily in isolation. Maternal factors could be responsible for this, such as congenital malformations of the uterus, prenatal malnutrition and lifestyle, maternal illnesses such as hypertension or diabetes in pregnancy, infection with bacterial vaginosis, malaria, and flu. Race, maternal age, socioeconomic factors, and parity are also contributory factors [14-16]. Incidence of low birth weight seems to be higher in teenage mothers, Blacks, and Asians.

Obstetric factors such as previous stillbirth, short birth interval, inadequate prenatal care, placenta previa, and abruption [17] could also be responsible. A clinical trial showed a $15 \%$ reduction in incidence of LBW when mothers were immunized with influenza vaccines [18]. Socioeconomic factors also play a critical role in low birth weight [19] as evidenced by a study in Iceland, which showed a significant rise in the incidence of preterm delivery after the severe economic decline affected young women who had no jobs especially in their $3^{\text {rd }}$ trimesters [20].

The outcomes of low birth weight are also dependent on other factors such as an enabling environment with adequate and effective perinatal and neonatal care, skilled birth attendants, and appropriate equipment and technological advancement in the care of such special cohort of newborns. In developed countries, survival rates of LBWs have improved due to the requisite skills and availability of appropriate equipment to support the low birth baby. Though the requisite skills and equipment might be lacking in the developing countries, the introduction of Kangaroo Mother Care has improved the survival rates in LBWs with comparable significantly better rates with the conventional methods [21].

In Africa, 5.7 million of LBW neonates are recorded every year [22]. In 2018, Nigeria recorded a prevalence of $7 \%$ LBW, with $7.5 \%$ of it in the urban and $6.9 \%$ of it in the rural [23]. The study on outcome of LBW is very important to ascertain improvement in maternal and neonatal health care services. Therefore, the objective of this study is to determine the outcome of LBW infants either born or referred to the Mother and Child Hospital, Akure, Ondo State.

\section{Material and Methods}

2.1. Study Area. The study was carried out at the Mother and Child Hospital, Akure (MCHA), a modern secondary public health facility providing specialized free health services to the state capital and surrounding communities. It also serves as a referral care center for other government, private, and missionary hospitals. The Mother and Child Hospital Akure is located in the city of Akure, the capital city of Ondo State. Ondo State lies between latitudes $5^{\circ} 45^{\prime}$ and $7^{\circ} 52^{\prime} \mathrm{N}$ and longitudes $4^{\circ} 20^{\prime}$ and $6^{\circ} 5^{\prime} \mathrm{E}$. Its land area is about 15,500 square kilometers. Ondo State has an estimated population of $5,372,477$, with over $1,715,820$ female inhabitants base on projection from the 2006 Nigeria national population.

2.2. Study Design and Population. This is an observational prospective study conducted on 540 neonatal admission for one year (May 2017 to April 2018). All the births were studied till either discharged from the hospital or inadvertent death.
2.3. Data Collection. A well-structured questionnaire was used for the collection of the socio-demography data of the baby's father and mother. Before applying the questionnaire to the target population, pretesting was carried out with twenty (20) women who are not part of the study group; this was to ascertain simplicity and the objective accuracy. A well-trained nurse and medical assistants were recruited to assist in administering the questionnaires and to conduct interviews for the parents and also in taking clinical and diagnostic data. Information collected included mother and father's age, educational level, occupation, marital status, antenatal visit, gestational age, neonate's birth weight, place of delivery, and days on admission was also monitored.

Each baby was weighed using the RGZ-20 weighing scale. The scale records weights in grams to the nearest $25 \mathrm{~g}$. It was adjusted for zero error before each reading. Other measures taken to ensure reliability of results included weekly standardization of the weighing scale, using known weights.

Physical examination and laboratory findings as well as clinical history were done to ascertain complications and it was carried out by the attending neonatologist. Some of the conditions were defined as follows:

(i) Apnoea defined as cessation of breathing lasting for 20 seconds or more, associated with bradycardia or cyanosis and needing resuscitation

(ii) Neonatal sepsis defined as clinical signs and symptoms suggestive of neonatal infections positive laboratory indices and multiple organ involvement

(iii) Neonatal jaundice is a yellowish discoloration of the sclera and skin and serum bilirubin up to $5 \mathrm{mg} / \mathrm{dl}$

(iv) Severe birth asphyxia defined as an APGAR score of 5 or less at 5 minutes and with neurological manifestations or babies with multiple organ involvement

(v) Hypoglycemia defined as random blood glucose of $<50 \mathrm{mg} / \mathrm{dl}$

(vi) Anemia defined as hemoglobin level $<10 \mathrm{~g} / \mathrm{dl}$

(vii) Hypothermia defined as a rectal temperature of $<35^{\circ} \mathrm{C}$

(viii) Failure-to-thrive (FTT) was used to describe inadequate growth, failure to gain weight or height, and the inability of the baby to maintain growth according to the standard growth chart; it is a sign of multiple problems as well as undernutrition

2.4. Inclusion Criteria. The enrollment was based on any live birth $<2,500 \mathrm{~g}$ in MCHA and neonates transferred in.

2.5. Exclusion Criteria. The excluded were children whose parents did not give their consent, babies with congenital abnormalities, and stillbirths.

2.6. Ethical Clearance. Ethical procedures were followed obtaining permission for the study from the Research and Ethics Committee in the MCHA. Informed consent was obtained from parents of participants. 
2.7. Data Analysis. Statistical analysis was carried on the collected data, using SPSS (version 21.0), and graphs were generated using Microsoft Excel. The chi-squared test was done to determine if gestational age and outcome of admission depend on mother's sociodemographic variables. The logistic regression procedure was used to determine the risk factors of LBW neonates in the studied area. Level of significance for this study is put at $p<0.05$.

\section{Results}

Table 1 shows the socio-demographic data of the neonates' parents in the MCHA. There were 137 low birth weight (LBW) neonates. More than half 87 (63.5\%) of the mothers were of age 30-39 years, with the mean age of $31.92 \pm 6.60$. Majority of the mothers were self-employed 80 (58.4\%), married $133(97.1 \%)$, and almost half $66(48.1 \%)$ of the mothers had tertiary education.

Table 2 shows that the mean age $\pm S D$ at presentation is $6 \pm 7.7$ days. Almost the same number of term 69 (50.4\%) and preterm $68(49.6 \%)$ was recorded. There were 64 female babies (46.7\%) and 73 male babies (53.3\%). The majority of LBW neonates were delivered by Spontaneous Vertex Delivery $116(84.7 \%)$. Also, the mean neonate's weight was $1.82 \pm 0.44 \mathrm{~kg}$ and mean of days on admission was $6.42 \pm 6.75$ days. Higher proportion of their mothers attended antenatal clinic 117 (85.4\%), before delivery.

Figure 1 shows that $100(73.0 \%)$ of the LBW neonates were discharged alive, 8 (5.8\%) were discharged against medical advice (DAMA), 9 (6.6\%) were referred, and 20 (14.6\%) of the LBW neonates died.

The disease spectrum of LBW neonates is shown in Table 3. Neonatal sepsis (NNS) had highest occurrence 79 (57.7\%) among the LBW neonates, followed by neonatal jaundice (NNJ) 48 (35.5\%), prematurity 47 (34.4\%), PROM 30 (21.9\%), Apnoea 22 (16.1\%), hypothermia 18 (13.1\%), respiratory distress syndrome 15 (10.9\%), hypoglycemia $10(7.3 \%)$, and haemorrhagic disease of the new born $3(2.2 \%)$.

Sex $\left(\chi^{2}=3.584, p=0.310\right)$, method of delivery $\left(\chi^{2}=4.669, p=0.198\right)$, and gestational age $\left(\chi^{2}=3.904\right.$, $p=0.272$ ) are not a significant determinant of outcome among LBW neonates, except neonate's weight $\left(\chi^{2}=21.216\right.$, $p=0.002$ ) (Table 4$)$. In Table 5 , the mother's age $30-39$ years and $40-49$ years were 1.82 and 2.39 times likely to deliver preterm babies, respectively, than 20-29 years of age. Neonates' sex was significantly associated with gestational age $(\mathrm{OR}=2.36,95 \% \mathrm{CL}=1.01-5.54, p=0.048)$ among LBW neonates. Also, the neonates' gestational age $\left(\chi^{2}=32.428\right.$, $p=0.001)$ significantly determined their weight.

PROM (60\%), hypothermia (72.2\%), apnoea (63.6\%), haemorrhagic disease-HDN (66.7\%), and respiratory distress syndrome-RDS (66.7\%) were more observed with preterm LBW neonates (Figure 2). In Figure 3, diseases that are more recorded with male LBW neonates were PROM (56.7\%), hypothermia (66.7\%), NNS (51.9\%), and RDS (60.0\%). Hypoglycemia (60.0\%), apnoea (54.5\%), HDN (66.7\%), RVS (66.7\%), and rhesus isoimmunization (100\%) were common with female LBW neonates.
TABLE 1: Socio-demographic data of the neonates' parents.

\begin{tabular}{|c|c|c|c|c|}
\hline Variable & & Frequency & Percent & Mean (SD) \\
\hline \multirow{3}{*}{ Mother's age } & 20-29 years & 42 & 30.7 & $31.92(6.60)$ \\
\hline & $30-39$ years & 87 & 63.5 & \\
\hline & 40-49 years & 8 & 5.8 & \\
\hline \multirow{4}{*}{$\begin{array}{l}\text { Mother's } \\
\text { occupation }\end{array}$} & $\begin{array}{c}\text { Self- } \\
\text { employed }\end{array}$ & 80 & 58.4 & \\
\hline & Student & 8 & 5.8 & \\
\hline & Employed & 35 & 25.5 & \\
\hline & Unemployed & 14 & 10.3 & \\
\hline \multirow{3}{*}{ Marital status } & Married & 133 & 97.1 & \\
\hline & Unmarried & 3 & 2.2 & \\
\hline & Separated & 1 & 0.7 & \\
\hline \multirow{3}{*}{$\begin{array}{l}\text { Mother's } \\
\text { education }\end{array}$} & Primary & 12 & 8.8 & \\
\hline & Secondary & 59 & 43.1 & \\
\hline & Tertiary & 66 & 48.1 & \\
\hline \multirow{4}{*}{ Father's age } & $20-29$ years & 9 & 6.6 & $37.18(5.81)$ \\
\hline & $30-39$ years & 74 & 54.0 & \\
\hline & $40-49$ years & 51 & 37.2 & \\
\hline & $\geq 50$ years & 3 & 2.2 & \\
\hline \multirow{4}{*}{$\begin{array}{l}\text { Father's } \\
\text { occupation }\end{array}$} & $\begin{array}{c}\text { Self- } \\
\text { employed }\end{array}$ & 68 & 49.6 & \\
\hline & Student & 2 & 1.5 & \\
\hline & Employed & 58 & 42.3 & \\
\hline & Unemployed & 9 & 6.6 & \\
\hline \multirow{3}{*}{$\begin{array}{l}\text { Father's } \\
\text { education }\end{array}$} & Primary & 9 & 6.6 & \\
\hline & Secondary & 53 & 38.7 & \\
\hline & Tertiary & 75 & 54.7 & \\
\hline
\end{tabular}

SD: standard deviation.

\section{Discussion}

Within the period of study, 540 neonates were admitted and majority of the neonates (75.9\%) were referred from other government hospitals to MCHA. The incidence of low birth weight (LBW) among the neonates in the current study was $25.37 \%$. This figure is higher than the reports of $2.6 \%$ in the 45 months of study from Enugu, southeast, and Nigeria [10], 6.3\% from Nsukka and Calabar [16], 8.3\% from PortHarcourt [24], and 15.7\% from Maiduguri [25]. Likewise, it is higher than report of $12.3 \%$ from Kenya in a cross-sectional analytical study conducted by Muchemi et al. [13] in Olkalou District Hospital and 14.6\% prevalence from a hospital-based observational study in Ethiopia by Melkamu et al. [17]. Higher incidence recorded in this study may be due to the fact that majority of the babies were referred in, MCHA being a major referral center and highly specialized for maternal and under- 5 care for other hospitals around the region. Again, the disparity in LBW prevalence across countries may be due to economic and environmental factors. According to Lee et al. [26], 14\% of neonates in lowincome countries were stated to have low birth weight $(<2,500 \mathrm{~g})$, with many of them born preterm. From the datasets of birth record collected by Fayehun and Asa [1] and from Nigeria Demographic and Health Survey (NDHS), the prevalence of LBW in urban areas was $18.3 \%$ between 2013 and 2018. Furthermore, the incidence of preterm in the current study was $49.6 \%$, which is comparatively higher than the previous report of $15.4 \%$ reported from the same center 
TABLE 2: Demographic and clinical status of LBW neonates in MCHA.

\begin{tabular}{|c|c|c|c|c|}
\hline Variable & & Frequency & Percentage & Mean (SD) \\
\hline \multirow{5}{*}{ Age at presentation } & $1-7$ days & 101 & 73.7 & $6.11(7.81)$ \\
\hline & 8-14 days & 16 & 11.7 & \\
\hline & 15-21 days & 15 & 11.0 & \\
\hline & $22-28$ days & 4 & 2.9 & \\
\hline & $>28$ days & 1 & 0.7 & \\
\hline \multirow{2}{*}{ Gestational age } & Term & 69 & 50.4 & \\
\hline & Preterm & 68 & 49.6 & \\
\hline \multirow{2}{*}{ Sex } & Female & 64 & 46.7 & \\
\hline & Male & 73 & 53.3 & \\
\hline \multirow{2}{*}{ Mode of delivery } & $\mathrm{CS}$ & 21 & 15.3 & \\
\hline & SVD & 116 & 84.7 & \\
\hline \multirow{3}{*}{ Neonate's weight (g) } & $600-<1000$ & 6 & 4.4 & $1.82(0.44)$ \\
\hline & $1000-1499$ & 23 & 16.8 & \\
\hline & $1500-2499$ & 108 & 78.8 & \\
\hline \multirow{4}{*}{ Days on admission } & $<8$ days & 101 & 73.7 & $6.42(6.75)$ \\
\hline & 8-14 days & 23 & 16.8 & \\
\hline & 15-21 days & 11 & 8.0 & \\
\hline & $>22$ days & 2 & 1.5 & \\
\hline \multirow{5}{*}{ Place of delivery } & Government hospital & 104 & 76.0 & \\
\hline & Private hospital & 7 & 5.1 & \\
\hline & Home & 11 & 8.0 & \\
\hline & Church/mission & 10 & 7.3 & \\
\hline & Farm & 5 & 3.6 & \\
\hline \multirow{2}{*}{ Antenatal care } & Yes & 117 & 85.4 & \\
\hline & No & 20 & 14.6 & \\
\hline
\end{tabular}

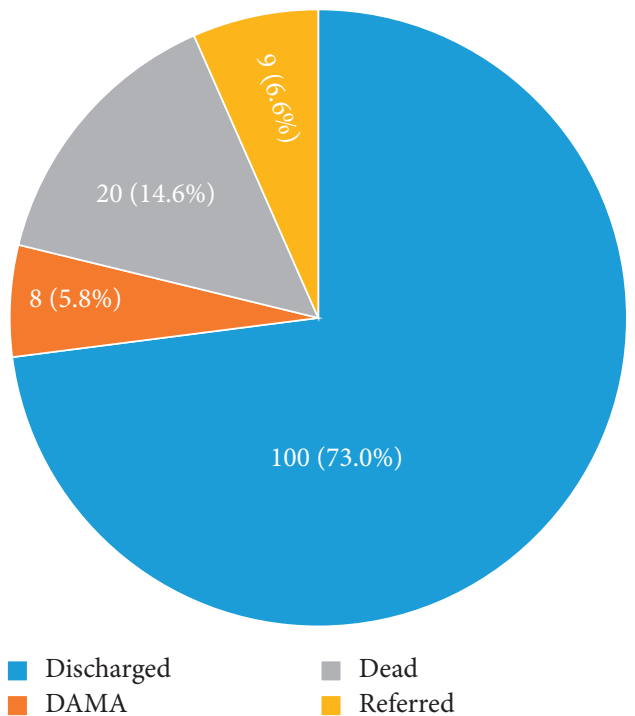

Figure 1: Outcome of LBW neonates in MCHA.

(MCHA), in 2016 [27] and of 18.5\% from Lagos [4] among babies delivered. The incidence of preterm was however lower than report of $90 \%$ from Enugu [10] and 68\% from Port-Harcourt [24].

In 2019, Melkamu et al. [17] reported factors that influenced LBW delivery to be mother's socio-demography status such as low maternal age, low level of education, and occupation (stressful job). Other factors identified by other researchers include maternal weight less than $50 \mathrm{~kg}$,
TABLE 3: Disease spectrum of LBW neonates in MCHA.

\begin{tabular}{lcc}
\hline Problems on admission & Frequency & Percentages \\
\hline Neonatal sepsis & 79 & 57.7 \\
Neonatal jaundice & 48 & 35.5 \\
Prematurity & 47 & 34.3 \\
Prolonged Rupture of Membranes & 30 & 21.9 \\
Apnoea & 22 & 16.1 \\
Hypothermia & 18 & 13.1 \\
Respiratory distress syndrome & 15 & 10.9 \\
Hypoglycemia & 10 & 7.3 \\
SBA/HIE & 10 & 7.3 \\
Others & 6 & 4.4 \\
Haemorrhagic disease of the newborn & 3 & 2.2 \\
Retroviral disease & 3 & 2.2 \\
Neonatal tetanus & 2 & 1.5 \\
Anorectal agenesis & 1 & 0.7 \\
Failure-to-Thrive & 1 & 0.7 \\
Rhesus isoimmunization & 1 & 0.7 \\
Dehydration fever & 1 & 0.7 \\
\hline
\end{tabular}

Others: postmaturity, aspiration pneumonitis, SBA: severe birth asphyxia, HIE: hypoxic ischemic encephalopathy LBW: low birth weight, MCHA: Mother and Child Hospital.

gestational age of baby ( $<37$ weeks), maternal anemia (hemoglobin less than $10 \mathrm{gm} / \mathrm{dl})$, maternal illness, multiple pregnancy, physical violence, exposure to environmental pollutants (pesticides), poor support from the husband or family, poverty, and nutrition (undernutrition, smoking of tobacco, alcohol ingestion, or iron deficiency) $[4,13,17,28-30]$. Meanwhile, in the current study, it was not 
TABLE 4: Determinant of outcome among LBW neonates in MCHA.

\begin{tabular}{|c|c|c|c|c|c|c|c|}
\hline \multirow{2}{*}{ Variables } & & \multicolumn{4}{|c|}{ Outcome } & \multirow{2}{*}{$\chi^{2}$} & \multirow{2}{*}{$p$ value } \\
\hline & & Discharge & DAMA & Referred & Dead & & \\
\hline \multirow{2}{*}{ Sex } & Female & $47(73.40 \%)$ & $2(3.10 \%)$ & $3(4.70 \%)$ & $12(18.8 \%)$ & \multirow[t]{2}{*}{3.584} & \multirow[t]{2}{*}{0.310} \\
\hline & Male & $53(72.60 \%)$ & $6(8.20 \%)$ & $6(8.20 \%)$ & $8(11.10 \%)$ & & \\
\hline \multirow{2}{*}{ Gestational age } & Term & $55(79.70 \%)$ & $2(2.90 \%)$ & $4(5.80 \%)$ & $8(11.60 \%)$ & \multirow[t]{2}{*}{3.904} & \multirow[t]{2}{*}{0.272} \\
\hline & Preterm & $45(66.20 \%)$ & $6(8.80 \%)$ & $5(7.40 \%)$ & $12(17.60 \%)$ & & \\
\hline \multirow{3}{*}{ Mode of delivery } & CS & $15(71.40 \%)$ & $3(14.30 \%)$ & $0(0.00 \%)$ & $3(14.30 \%)$ & \multirow[t]{2}{*}{4.669} & \multirow[t]{2}{*}{0.198} \\
\hline & SVD & $85(73.30 \%)$ & $5(4.30 \%)$ & $9(7.8 \%)$ & $17(14.70 \%)$ & & \\
\hline & $600-999$ & $3(50.00 \%)$ & $0(0.00 \%)$ & $0(0.00 \%)$ & $3(50.00 \%)$ & \multirow[t]{3}{*}{21.216} & \multirow[t]{3}{*}{$0.002^{*}$} \\
\hline \multirow[t]{2}{*}{ Neonate's weight (g) } & $1000-1499$ & $10(43.50 \%)$ & $2(8.70 \%)$ & $3(13.0 \%)$ & $8(34.80 \%)$ & & \\
\hline & $1500-2499$ & $87(80.60 \%)$ & $6(5.60 \%)$ & $6(5.60 \%)$ & $9(8.30 \%)$ & & \\
\hline
\end{tabular}

$\chi^{2}$ : chi square, ${ }^{*}$ : significant $(p<0.05)$.

TABLE 5: Determinant of gestational age among LBW neonates in MCHA.

\begin{tabular}{|c|c|c|c|c|c|c|}
\hline \multirow{2}{*}{ Variables } & & \multicolumn{2}{|c|}{ Gestational age } & \multirow{2}{*}{$\chi^{2}$} & \multirow{2}{*}{$p$ value } & \multirow{2}{*}{ OR $(95 \%$ C. I. for $\operatorname{EXP}(B))$} \\
\hline & & Term & Preterm & & & \\
\hline \multirow{3}{*}{ Mother's age (years) } & $20-29$ & $23(54.80 \%)$ & $19(45.20 \%)$ & 0.477 & 0.788 & \\
\hline & $30-39$ & $42(48.30 \%)$ & $45(51.70 \%)$ & & & $1.82(0.69-4.80)$ \\
\hline & $40-49$ & $4(50.00 \%)$ & $4(50.00 \%)$ & & & $2.39(0.41-14.21)$ \\
\hline \multirow{4}{*}{ Mother's occupation } & Self-employed & $39(48.80 \%)$ & $41(51.30 \%)$ & 0.571 & 0.903 & $1.61(0.38-6.66)$ \\
\hline & Student & $5(62.50 \%$ & $3(37.50 \%)$ & & & $0.62(0.05-6.96)$ \\
\hline & Employed & $18(51.40 \%)$ & $17(48.60 \%)$ & & & $1.08(0.22-5.20)$ \\
\hline & Unemployed & $7(50.00 \%)$ & $7(50.00 \%)$ & & & \\
\hline \multirow{3}{*}{ Mother's education } & Primary & $5(41.70 \%)$ & $7(58.30 \%)$ & 0.479 & 0.787 & \\
\hline & Secondary & $31(52.50 \%)$ & $28(47.50 \%)$ & & & $0.88(0.19-4.18)$ \\
\hline & Tertiary & $33(50.00 \%)$ & $33(50.00 \%)$ & & & $0.66(0.13-3.40)$ \\
\hline \multirow{3}{*}{ Neonates' sex } & Female & $36(56.30 \%)$ & $28(43.80 \%)$ & 1.664 & 0.197 & \\
\hline & Male & $33(45.20 \%)$ & $40(54.80 \%)$ & & & $2.36(1.01-5.54)^{*}$ \\
\hline & $600-999$ & $0(0.00 \%)$ & $6(100.00 \%)$ & 32.428 & $0.001^{*}$ & \\
\hline \multirow[t]{2}{*}{ Neonate's weight (g) } & $1000-1499$ & $1(4.30 \%)$ & $22(95.70 \%)$ & & & \\
\hline & $1500-2499$ & $68(63.00 \%)$ & $40(37.00 \%)$ & & & \\
\hline
\end{tabular}

$\chi^{2}$ : chi square, ${ }^{*}$ : significant $(p<0.05)$, OR: odd ratio.

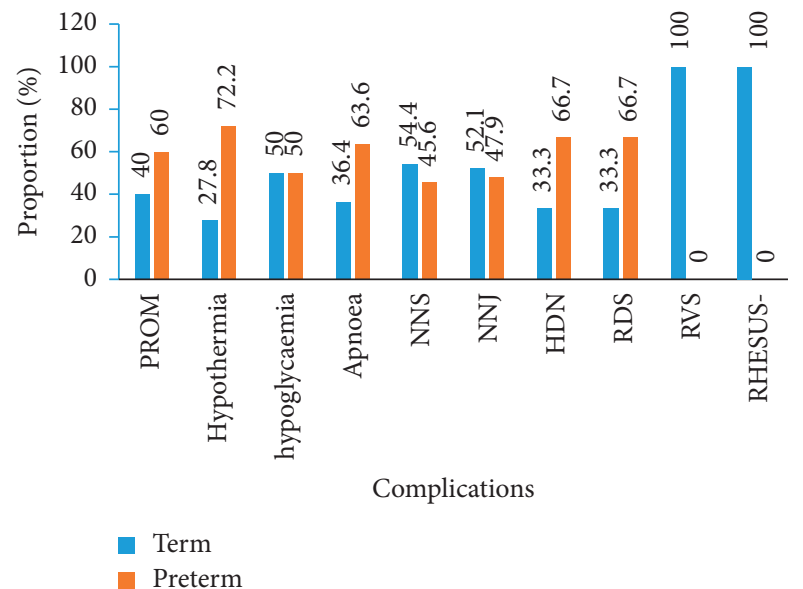

Figure 2: Diseases associated with gestational age.

significantly evident that mothers' age contributed to LBW neonates, but it was observed that most of LBW neonates' mothers were between 30 and 39 years old, with a mean age of $31.92 \pm 6.60$. Goisis et al. [15] reported that there was no association between advanced maternal age and low birth weight or preterm among Finnish mothers and in contrast,

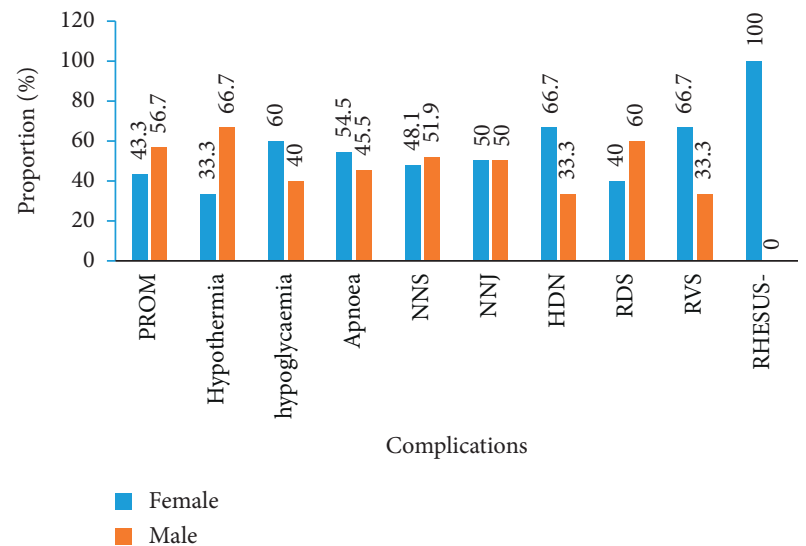

FIgURE 3: Diseases associated with neonates' sex.

Alehegn et al. [31] noted that age 40 and above were more prone to have LBW newborns compared to a maternal age of 30-34 years. On the other hand, the mother's age less than 19 years old was revealed to be more of risk of delivering LBW babies because their reproductive system might not have fully developed and also likely due to economic deficiency and selfneglect $[29,32]$ in terms of health care. The difference on this 
view of maternal age and LBW may be due to other factors that may influence LBW but not observed in each study.

Mothers with secondary and tertiary education were 0.88 and 0.66 time, respectively, less likely to experience low birth weight delivery than mothers with lower educational levels. In accordance with this study, reports by Maznah et al. [33] on 2013 Nigeria Demographic and Health Survey show that maternal education has a significant association with birth weight of their infants. Silvestrin et al. [34] also opined that having a higher education serves as protection against LBW delivery than having a lower education. Higher education increases the mothers' level of awareness and understanding, thereby helps in safeguarding mothers from careless attitude about their health. In contrary, some other researchers revealed from their study that a mother's level of education has no significant effect on birth weight $[35,36]$.

Also, in the current study, majority of the mothers of the low birth weight babies had ANC; this is contrary to a study by Yaya et al. [37] where participants who do not receive ANC had a higher odds of a low birth weight or preterm baby. In 2016, WHO made an adjustment on the minimum number of ANC contacts recommended for pregnant woman from 4 times to 8 times [38]. It is expected that during ANC periods, risk for delivery should be identified, prevented, and managed [39]. Analysis of community-based study in seven Western provinces of China by Ref. [40] reported that mothers who did not make up to five ANC contacts during pregnancy had a higher risk of LBW babies than mothers who had it and also added the importance of the ANC to be an ultimate contributor to avoid LBW and other complications, through early detection that leads to timely diagnoses and therapeutic intervention. The disagreement of this study to other studies concerning the ANC in relation to LBW may be due to the fact that this study did not examine the number of ANC received by neonate's mothers. On the other hands, mothers who attested to taking ANC might not have had the minimum required ANC contacts or might not have followed recommendations made during ANC session due to economic or financial constraints. Components of antenatal care (services render) differ from place to place [41]. LBW delivery is also possible because some of the mothers did not enroll in appropriate health facilities as many were captured to have delivered their babies at Church/mission (7.3\%), home or traditional home (8.0\%), and farm (3.6\%). Likewise, Branco da Fonseca et al. [42] affirmed that not having adequate number of antenatal care visits is associated with low birth weight.

Furthermore, working mothers were 5 times more likely prone to have a low birth weight infant than the housekeeper and self-employed mothers [43,44]. In the low-economy countries where government work is not readily available or mother's education cannot secure a good job, in order for mothers to assist their husband or meet up with standard of living, they engaged in strenuous work (even when pregnant) like standing for long hours, hawking, lifting objects, and physical hard works. These strenuous works have been associated with outcomes (preterm and LBW) and complications in the neonates [45]. Working more than 8 hours per week may lead to low birth weight [44].
Extreme low birth weight (ELBW) neonates recorded in this study were $100 \%$ preterm, while the very low birth weight (VLBW) was $95.7 \%$ preterm. This shows that the low birth weight is strongly associated with gestational age. Several other researchers have also affirmed it $[4,30,35,46,47]$.

There was a slightly higher number $(53.3 \%)$ of a male LBW neonate in this study. The binary logistic analysis further revealed that male babies were 2.36 times preterm than their female counterpart. Several researchers have corroborated this finding [48-50]. Reports by Kramer pointed out that the male genes are a significant contributing factor to being born as a low birth weight [51]. While other evidence suggested that male preterm birth is due to hormonal action, more inflammatory maker in the placental bed of the male fetus and that mothers of male fetuses showed more adverse reactions to these markers and these mothers are more prone to complications [52-54]. In contrast, female neonates were 1.62 times more likely to be born with low weights and preterm in a study conducted by Melkamu et al. [17]. However, there were a higher number of deaths (60\%) recorded among female LBW neonates. RVS, rhesus isoimmunization, HDN, apnoea, and hypoglycemia were complications that were more associated to female LBW neonates in this study.

The immediate outcomes of the LBWs showed that $80.6 \%$ of babies in the range of $1500-2499 \mathrm{~g}$ were discharged alive from the hospital and are in keeping with the study done in National Institute of Child Health by the American Association of Pediatricians where it was proven that outcomes improved significantly with birth weights. In addition to this, Lemons et al. [21] recorded 97\% discharge among $1251-1500 \mathrm{~g}$ and $54 \%$ among the $501-750 \mathrm{~g}$. In the current study, $80.6 \%$ of the LBW were discharged alive and only $1.6 \%$ died while there was $50 \%$ survival and $50 \%$ deaths among the babies whose weight ranged between 600 and $999 \mathrm{~g}$. This is an improvement in survival rate of the ELBW compared to $70.6 \%$ mortality in the previous study conducted earlier on in the same center [27].

In the current study, $6.6 \%$ of the studied LBW neonates were later referred to the surgical unit for surgical interventions. Overall, there was $14.6 \%$ mortality. Neonatal death recorded in this study is very low compared to $30 \%$ death reported by Chidiebere et al. [10] from a health facility in South East of Nigeria. Total discharged was $73.0 \%$ of LBW neonates admitted, and mean of days on admission of LBW neonates recruited was $6.42 \pm 6.72$. There were 2 of them that spent more than 22 days on admission. This higher number of discharge was also reported by Koc et al. [55], where 3381 (77.99\%) VLBW infants were discharged out of 4335 VLBW infants admitted in neonatal intensive care units (NICUs) in Turkey, and also recorded $22 \%$ mortality during their study. Neonates and infant's death have been associated with low birth weight, and according to Elflein [56], 16.5\% of all infant deaths in the United States is as a result of LBW.

Among the disease spectrum associated with LBW babies, neonatal sepsis ranked highest at $57.7 \%$ in the current study. This is not surprising; many of the babies were born in unusual places such as Church, home, and farm. 
Essential newborn care (drying, warming, immediate and exclusive breastfeeding, hygiene, and cord care) as well as basic care for feeding support, infection control, and breathing support which can make the difference between life and death for small babies cannot be found in these places. The current study also reported morbidities such as hypoglycemia $(7.3 \%)$, hypothermia (13.1\%), and apnoea (16.1\%). LBW newborns are particularly susceptible to heat loss immediately after birth as a result of a high body surface area-to-body weight ratio, decreased brown fat stores, nonkeratinized skin, and decreased glycogen store [10]. All these happen as a cascade leading to hypoglycemia and apnoea coupled with immaturity of the brain and multiple ischemic brain injuries caused by recurrent hypoxic and bradycardiac spells. These have also been reported by other researchers [10, 55, 57-59]. This is unlike the study by Lemons et al. [21] where acute pulmonary disease was the highest comorbidity among the LBW babies. These differences could be due to environmental factors and a probable infection prevention and control practices.

\section{Conclusions}

The number of dead neonates in this study is still of concern, and amelioration of survival rate of low birth weight babies is important in our society. More emphasis should be placed on the importance of qualitative antenatal care (ANC) for the pregnant women. This will foster education among women for early prevention, detection, and better management and consequently better outcomes of LBW neonates.

\section{Abbreviations}

MCHA: Mother and Child Hospital Akure

DAMA: Discharged against medical advice

NNS: Neonatal sepsis

FTT: Failure-to-Thrive

ELBW: Extremely low birth weight

VLBW: Very low birth weight

SBA: $\quad$ Severe birth asphyxia

NEC: Necrotizing enterocolitis

SGA: Small for gestational age

NNJ: Neonatal jaundice

NNT: Neonatal tetanus

HIE: Hypoxic ischemic encephalopathy

RDS: Respiratory distress syndrome

PROM: Premature rupture of membranes

NNEC: Neonatal necrotizing enterocolitis

HDN: Haemorrhagic disease of the new born

RVS: Retroviral disease.

\section{Data Availability}

The data are not available due to ethical concerns.

\section{Conflicts of Interest}

The authors declare that they have no conflicts of interest.

\section{References}

[1] O. Fayehun and S. Asa, "Abnormal birth weight in urban Nigeria: an examination of related factors," PLoS One, vol. 15, no. 11, Article ID e0242796, 2020.

[2] F. Agbozo, A. Abubakari, J. Der, and A. Jahn, "Prevalence of low birth weight, macrosomia and stillbirth and their relationship to associated maternal risk factors in Hohoe $\mathrm{Mu}$ nicipality, Ghana," Midwifery, vol. 40, pp. 200-206, 2016.

[3] H. G. Mengesha, A. D. Wuneh, B. Weldearegawi, and D. L. Selvakumar, "Low birth weight and macrosomia in Tigray, Northern Ethiopia: who are the mothers at risk?" BMC Pediatrics, vol. 17, no. 44, pp. 1-9, 2017.

[4] R. Oluwafemi, O. Njokanma, E. Disu, and T. Ogunlesi, "Maternal factors in the aetiology of small-for-gestational age among term Nigerian babies," Nigerian Journal of Paediatrics, vol. 40, no. 2, pp. 119-124, 2013.

[5] J. E. Siza, "Risk factors associated with low birth weight of neonates among pregnant women attending a referral hospital in northern Tanzania," Tanzania Journal of Health Research, vol. 10, no. 1, pp. 1-8, 2008.

[6] H. Watanabe, "The effect of prepregnancy body mass index and gestational weight gain on birth weight," INTECH Open Access Publisher, vol. 38, no. 3, pp. 120-129, 2008.

[7] Y. Gebregzabiherher, A. Haftu, S. Weldemariam, and H. Gebrehiwet, "The prevalence and risk factors for low birth weight among term newborns in adwa general hospital, northern Ethiopia," Obstetrics and Gynecology International, vol. 2017, Article ID 2149156, 7 pages, 2017.

[8] G. Singh, R. Chouhan, and K. Sidhu, "Maternal factors for low birth weight babies," Medical Journal Armed Forces India, vol. 65, no. 1, pp. 10-12, 2009.

[9] R. A. Mahumud, M. Sultana, and A. R. Sarker, "Distribution and determinants of low birth weight in developing countries," Journal of Preventive Medicine and Public Health, vol. 50, no. 1, pp. 18-28, 2017.

[10] O. D. Chidiebere, U. Ekwochi, I. K. Ndu et al., "The low-birth weight infants: pattern of morbidity and mortality in a tertiary healthcare facility in the South eastern Nigeria," Annals of Medical and Health Sciences Research, vol. 8, pp. 4-10, 2018.

[11] P. Anderson, L. W. Doyle, E. Carse, and M. P. Charlton, "Neurobehavioral outcomes of school-age children born extremely low birth weight or very preterm in the 1990s," JAMA, vol. 289, no. 24, pp. 3264-3272, 2003.

[12] World health Organization, "WHA global nutrition targets 2025: low birth weight policy brief," 2014, https://www.who. int/nutrition/topics/globaltargets_lowbirthweight_ policybrief.pdf.

[13] O. M. Muchemi, E. Echoka, and A. Makokha, "Factors associated with low birth weight among neonates born at Olkalou District Hospital, Central Region, Kenya," The Pan African medical journal, vol. 20, no. 108, pp. 108-11, 2015.

[14] H. Demelash, D. Nigatu, K. Gashaw, K. Gashaw, and A. Melese, "A case-control study on intimate partner violence during pregnancy and low birth weight, southeast Ethiopia," Obstetrics and Gynecology International, vol. 2015, no. 264, 6 pages, Article ID 394875, 2015.

[15] A. Goisis, H. Remes, K. Barclay, P. Martikainen, and M. Myrskylä, "Advanced maternal age and the risk of low birth weight and preterm delivery: a within-family analysis using Finnish population registers," American Journal of Epidemiology, vol. 186, no. 11, pp. 1219-1226, 2017.

[16] N. U. Igboeli, M. O. Adibe, C. V. Ukwe, and N. C. Aguwa, "Prevalence of low birth weight before and after policy change 
to IPTp-SP in two selected hospitals in southern Nigeria: eleven-year retrospective analyses," BioMed Research International, vol. 2018, Article ID 4658, , 2018.

[17] B. Melkamu, W. Netsanet, G. Tsinuel et al., "Prevalence of low birth weight and prematurity and associated factors in neonates in Ethiopia: results from a hospital-based observational study," Ethiopian Journal of Health Science, vol. 29, no. 6, pp. 677-688, 2019.

[18] A. C. Agudelo, "Kangaroo mother care to reduce morbidity and mortality in low birth weight infants," Cochrane database of systemic reviews, vol. 8, pp. 1-119, Article ID CD002771, 2016.

[19] C. E. Margerison-Zilko, R. Catalano, A. Hubbard, and J. Ahern, "Maternal exposure to unexpected economic contraction and birth weight for gestational age," Epidemiology, vol. 22, no. 6, pp. 855-858, 2011.

[20] V. H. Eiríksdóttir, T. L. Ásgeirsdóttir, R. I. Bjarnadóttir, R. Kaestner, S. Cnattingius, and U. A. Valdimarsdóttir, "Low birth weight, small for gestational age and preterm births before and after the economic collapse in Iceland: a population based cohort study," PLoS One, vol. 8, no. 12, Article ID e80499, 2013.

[21] J. A. Lemons, C. R. Bauer, W. Oh et al., "Very low birth weight outcomes of the National Institute of Child health and human development neonatal research network, January 1995 through December 1996. NICHD Neonatal Research Network," Pediatrics, vol. 107, no. 1, p. E1, 1996.

[22] Unicef Who, Low Birth Weight Estimates: Levels and Trends 2000-2015, WHO, Geneva, Switzerland, 2019.

[23] I. C. F. National Population Commission (Npc) [Nigeria], Nigeria Demographic Health Survey 2018, DHS Progr ICF, Rockville, ML, USA, 2019.

[24] H. Ugboma and C. Onyearugha, "Low birthweight delivery: prevalence and associated factors as seen at a tertiary health facility," Nigerian Journal of Clinical Practice, vol. 16, no. 2, pp. 184-187, 2013.

[25] I. Takai, B. Audu, and M. Bukar, "A prospective study of maternal risk factors for low birth weight babies in Maiduguri, North-Eastern Nigeria," Nigerian Journal of Basic and Clinical Sciences, vol. 11, no. 2, pp. 89-98, 2014.

[26] A. C. Lee, J. Katz, H. Blencowe et al., "National and regional estimates of term and preterm babies born small for gestational age in 138 low-income and middle-income countries in 2010," Lancet Global Health, vol. 1, no. 1, pp. e26-e36, 2013.

[27] R. O. Oluwafemi and M. T. Abiodun, "Incidence and outcome of preterm deliveries in mother and child hospital akure, southwestern Nigeria," Sri Lanka Journal of Child Health, vol. 45, no. 1, pp. 11-17, 2016.

[28] S. R. Sharma, S. Giri, U. Timalsina et al., "Low birth weight at term and its determinants in a tertiary hospital of Nepal: a case-control study," PLoS One, vol. 10, no. 4, Article ID e0123962, 2015.

[29] Z. Adam, D. K. Ameme, P. Nortey, E. A. Afari, and E. Kenu, "Determinants of low birth weight in neonates born in three hospitals in Brong Ahafo region, Ghana, 2016- an unmatched case-control study," BMC Pregnancy and Childbirth, vol. 19, no. 1, p. $174,2019$.

[30] C. Xi, M. Luo, T. Wang et al., "Association between maternal lifestyle factors and low birth weight in preterm and term births: a case-control study," Reproductive Health, vol. 17, no. 93, pp. 93-99, 2020.

[31] B. Alehegn, S. Girma, T. Kiflome, and F. Yitbarek, "The effects of maternal age and parity on the birth weight of newborns among mothers with singleton pregnancies and at term deliveries," The Ethiopian Journal of Health Development, vol. 33, no. 3, pp. 182-187, 2019.

[32] A. M. Guimarães, N. d'Avila, H. Bettiol et al., "Is adolescent pregnancy a risk factor for low birth weight?" Revista de Saúde Pública, vol. 47, no. 1, pp. 11-19, 2013.

[33] D. Maznah, A. Nazar, M. O. Oche, and A. A. Norlaili, "Risk factors for low birth weight in Nigeria: evidence from the 2013 Nigeria Demographic and Health Survey," Global Health Action, vol. 9, Article ID 28822, 2016.

[34] S. Silvestrin, C. H. da Silva, V. N. Hirakata, A. A. S. Goldani, P. P. Silveira, and M. Z. Goldani, "Maternal education level and low birth weight: a meta-analysis," Jornal de Pediatria, vol. 89, no. 4, pp. 339-345, 2013.

[35] H. B. Oladeinde, O. B. Oladeinde, R. Omoregie, and A. A. Onifade, "Prevalence and determinants of low birth weight: the situation in a traditional birth home in Benin City, Nigeria," African Health Sciences, vol. 15, no. 4, pp. 1123-1129, 2015.

[36] A. K. Manyeh, V. Kukula, G. Odonkor et al., "Socioeconomic and demographic determinants of birth weight in southern rural Ghana: evidence from Dodowa Health and Demographic Surveillance System," BMC Pregnancy and Childbirth, vol. 16, no. 1, p. 160, 2016.

[37] S. Yaya, G. Bishwajit, M. Ekholuenetale, and V. Shah, "Inadequate utilization of prenatal care services, socioeconomic status, and educational attainment are associated with low birth weight in Zimbabwe," Frontiers in Public Health, vol. 5, no. 35, pp. 1-7, 2017.

[38] S. S. Jiwani, A. Amouzou-Aguirre, L. Carvajal et al., "Timing and number of antenatal care contacts in low and middleincome countries: analysis in the Countdown to 2030 priority countries," Journal of Global Health, vol. 10, no. 1, Article ID 010502, 2020.

[39] World Health Organization, WHO Antenatal Care Randomized Trial: Manual for the Implementation of the New Model, World health Organization, Geneva, Switzerland, 2002.

[40] H. Zhou, A. Wang, X. Huang et al., "Quality antenatal care protects against low birth weight in 42 poor counties of Western China," PLoS One, vol. 14, no. 1, Article ID e0210393, 2019.

[41] P. K. Appiah, M. Bukari, S. N. Yiri-Erong et al., "Antenatal care attendance and factors influenced birth weight of babies born between june 2017 and may 2018 in the wa East District, Ghana," International Journal of Reproductive Medicine, vol. 2020, Article ID 1653076, 10 pages, 2020.

[42] C. R. Branco da Fonseca, M. W. L. Strufaldi, L. R. de Carvalho, and R. F. Puccini, "Adequacy of antenatal care and its relationship with low birth weight in Botucatu, São Paulo, Brazil: a case-control study," BMC Pregnancy and Childbirth, vol. 14, no. 255, pp. 1-12, 2014.

[43] X. Li, J. Sundquist, and K. Sundquist, "Parental occupation and risk of small-for-gestational-age births: a nationwide epidemiological study in Sweden," Human Reproduction, vol. 25, no. 4, pp. 1044-1050, 2010.

[44] Z. Mahmoodi, M. Karimlou, H. Sajjadi et al., "Association of maternal working condition with low birth weight: the social determinants of health approach," Annals of Medical and Health Sciences Research, vol. 5, no. 6, pp. 385-391, 2015.

[45] M. A. Q. Mutsaerts, H. Groen, A. Buiter-Van der Meer et al., "Effects of paternal and maternal lifestyle factors on pregnancy complications and perinatal outcome. A populationbased birth-cohort study: the GECKO Drenthe cohort," Human Reproduction, vol. 29, no. 4, pp. 824-834, 2014. 
[46] World Health Organization, "Care of the preterm and lowbirth-weight newborn," 2018, https://www.who.int/maternal_ child_adolescent/newborns/prematurity/en/.

[47] M. B. Bekela, M. S. Shimbre, T. F. Gebabo et al., "Determinants of low birth weight among newborns delivered at public hospitals in sidama zone, South Ethiopia: unmatched casecontrol study," Journal of Pregnancy, vol. 2020, Article ID 4675701, 8 pages, 2020.

[48] R. Brettell, P. S. Yeh, and L. W. M. Impey, "Examination of the association between male gender and preterm delivery," European Journal of Obstetrics \& Gynecology and Reproductive Biology, vol. 141, no. 2, pp. 123-126, 2008.

[49] N. Melamed, Y. Yogev, and M. Glezerman, "Fetal gender and pregnancy outcome," Journal of Maternal-Fetal and Neonatal Medicine, vol. 23, no. 4, pp. 338-344, 2010.

[50] M. J. C. S. Peelen, B. M. Kazemier, A. C. J. Ravelli et al., "Impact of fetal gender on the risk of preterm birth, a national cohort study," Acta Obstetricia et Gynecologica Scandinavica, vol. 95, no. 9, pp. 1034-1041, 2016.

[51] M. S. Kramer, "Determinants of low birth weight: methodological assessment and meta-analysis," Bulletin of the World Health Organization, vol. 65, no. 5, pp. 663-737, 1987.

[52] M. Cooperstock and J. Campbell, "Excess males in preterm birth: interactions with gestational age, race, and multiple birth," Obstetrics \& Gynecology, vol. 88, no. 2, pp. 189-193, 1996.

[53] V. L. Clifton, "Review: sex and the human placenta: mediating differential strategies of fetal growth and survival," Placenta, vol. 31, 2010.

[54] J. Challis, J. Newnham, F. Petraglia, M. Yeganegi, and A. Bocking, "Fetal sex and preterm birth," Placenta, vol. 34, no. 2, pp. 95-99, 2013.

[55] E. Koc, N. Demirel, A. Y. Bas et al., "Early neonatal outcomes of very-low-birth-weight infants in Turkey: a prospective multicenter study of the Turkish Neonatal Society," PLoS One, vol. 14, no. 12, Article ID e0226679, 2019.

[56] J. Elflein, "Leading causes of infant death in the United States 2019," 2021, https://www.statista.com/statistics/946675/ leading-causes-of-infant-death-in-the-us/.

[57] A. Jancevska, V. Tasic, N. Damcevski, D. Danilovski, V. Jovanovska, and Z. Gucev, "Children born small for gestational age (SGA)," Contributions of Institute of Archaeology in Zagreb, vol. 33, no. 2, pp. 47-58, 2012.

[58] C. A. Negrato and M. B. Gomes, "Low birth weight: causes and consequences," Diabetology \& Metabolic Syndrome, vol. 5, no. 1, p. 49, 2013.

[59] M. Desta, Low birth weight and adverse perinatal outcomes, M. Z. Jovandaric and S. J. Milenkovic, Eds., In Childbirth, London, UK, 2019. 